\title{
Highly selective synthesis of (E)-alkenyl-(pentafluorosulfanyl)benzenes through Horner-Wadsworth-Emmons reaction
}

George lakobson and Petr Beier*

Open Access

\author{
Full Research Paper \\ Address: \\ Institute of Organic Chemistry and Biochemistry, Academy of \\ Sciences of the Czech Republic, Flemingovo nám. 2, 16610 Prague, \\ Czech Republic \\ Email: \\ Petr Beier* - beier@uochb.cas.cz \\ * Corresponding author \\ Keywords: \\ Horner-Wadsworth-Emmons reaction; pentafluorosulfanyl group; \\ phosphonates; sulfurpentafluoride
}

Beilstein J. Org. Chem. 2012, 8, 1185-1190.

doi:10.3762/bjoc.8.131

Received: 31 May 2012

Accepted: 27 June 2012

Published: 25 July 2012

Associate Editor: D. O'Hagan

(C) 2012 lakobson and Beier; licensee Beilstein-Institut. License and terms: see end of document.

\begin{abstract}
Diethyl 2-nitro-(pentafluorosulfanyl)benzylphosphonates, available by the vicarious nucleophilic substitution reaction of meta- and para-nitro-(pentafluorosulfanyl)benzenes and diethyl chloromethylphosphonate, undergo Horner-Wadsworth-Emmons reaction with aldehydes in the presence of potassium hydroxide in acetonitrile at ambient temperature to give (E)-2-nitro-1-alkenyl-(pentafluorosulfanyl)benzenes in good yields and high stereoselectivities. Follow-up transformations of the primary products provided (E)-1-alkenyl-(pentafluorosulfanyl)benzenes and 2-(2-arylethyl)-(pentafluorosulfanyl)anilines.
\end{abstract}

\section{Introduction}

Although the pentafluorosulfanyl $\left(\mathrm{SF}_{5}\right)$ containing compounds have been known for more than half a century [1-4], they remain a relatively underdeveloped class of compounds. This is so despite the unusual combination of properties that the $\mathrm{SF}_{5}$ group possesses, such as high thermal and chemical stability, high electronegativity and strong lipophilic character [2-7]. The availability of $\mathrm{SF}_{5}$-containing compounds is very limited. Aliphatic $\mathrm{SF}_{5}$-containing compounds are available through freeradical addition of toxic and expensive $\mathrm{SF}_{5} \mathrm{Cl}$ to unsaturated compounds [8,9], and aromatic meta- and para-nitro-(pentafluorosufanyl)benzenes ( $\mathbf{1}$ and $\mathbf{2}$ ) are made by direct fluorin- ation of the corresponding bis(nitrophenyl)disulfides [10-12]. A recent report also described a two step synthesis of $\mathrm{SF}_{5}$ benzenes from diaryl disulfides avoiding the use of elemental fluorine [13]. While the only known $S_{E} A r$ of $\mathbf{1}$ or $\mathbf{2}$ is the nitration of 2 under harsh conditions and in low yield [14], we have recently described $\mathrm{S}_{\mathrm{N}} \mathrm{Ar}$ of the nitro group in compounds $\mathbf{1}$ and 2 with alkoxides and thiolates [15], vicarious nucleophilic substitution (VNS) of the hydrogen with carbon [16], oxygen [17] and nitrogen [18] nucleophiles, and the oxidative nucleophilic substitution with Grignard and alkyllithium reagents [19]. Reduction of the nitro group in $\mathbf{1}$ or $\mathbf{2}$ to (pentafluorosul- 
fanyl)anilines followed by acylation, $\mathrm{S}_{\mathrm{E}} \mathrm{Ar}$ halogenation or diazotization (with follow-up reactions) has also been described $[11,20-22]$.

Alkenyl substituted $\mathrm{SF}_{5}$-benzenes or $\mathrm{SF}_{5}$-containing stilbene derivatives are not known and would represent basic synthetic intermediates towards more elaborate structures. We envisioned a synthetic route towards these compounds through Horner-Wadsworth-Emmons (HWE) reaction of phosphonates $\mathbf{3}$ and $\mathbf{4}$, which are available by vicarious nucleophilic substitution (VNS) of commercial nitrobenzenes $\mathbf{1}$ and $\mathbf{2}$ with diethyl chloromethylphosphonate [16]. If required, the nitro group can be removed by a reduction/diazotization/reduction sequence before or after the HWE reaction (Scheme 1).

The HWE reaction is a modification of the Wittig olefination in which a phosphoryl-stabilized carbanion reacts with an aldehyde or ketone to form an alkene and a water-soluble phosphate ester [23-25]. In general, this reaction preferentially gives more stable $E$-disubstituted alkenes, although several successful attempts have been made to favor $Z$-alkenes [26-28].

\section{Results and Discussion}

The HWE reaction of phosphonate $\mathbf{3}$ with benzaldehyde in the presence of a base giving stilbene derivative 5a was investigated. At first, attempts were made to form $\mathbf{5 a}$ directly from $\mathbf{1}$ and diethyl chloromethylphosphonate by a two-step one-pot process, involving VNS reaction in DMF with a three-fold excess of $t$-BuOK $\left(-60^{\circ} \mathrm{C}, 10 \mathrm{~min}\right)$, followed by the addition of benzaldehyde (1.5 equiv) and warming of the reaction mixture to $50{ }^{\circ} \mathrm{C}$ (Table 1 , entry 1 ). These conditions provided the expected 5a in good GCMS yield and high $E / Z$ selectivity, but called for rather long reaction time. By changing the solvent from DMF to THF, we observed a less efficient first step (the VNS reaction) with many unidentified side products being formed (Table 1, entry 2). Therefore, all other experiments were carried out starting from isolated phosphonate 3 . We found that various bases mediate the HWE reaction. $t$-BuOK in THF gave good results; however, the reaction required heating to $50{ }^{\circ} \mathrm{C}$ for at least one hour. With $n$-BuLi the reaction is complete at ambient temperature in about half an hour. By using an extended reaction time, much less basic potassium or caesium carbonate in acetonitrile could also be used successfully. Finally, we have identified potassium hydroxide as a very inexpensive and convenient base. The best results were obtained by using 1.8 equiv of $\mathrm{KOH}$ in acetonitrile. The addition of small amounts of water increased the reaction rate, presumably by better solubilization of $\mathrm{KOH}$ and the formed potassium diethylphosphate, and gave the required product 5a in $84 \%$ isolated yield and high $E / Z$ selectivity (Table 1, entry 13 ).

Using optimized reaction conditions (Table 1, entry 13), the scope of the HWE reaction of various aldehydes with phosphonate 3 was explored (Table 2). Aromatic aldehydes with electron-donating groups required longer reaction times than those with electron-acceptor groups. All tested aromatic aldehydes provided compounds $\mathbf{5}$ in high isolated yields and selectivities. Application of (E)-cinnamaldehyde (3f) led to the formation of $\mathbf{5 f}$ in only $43 \%$ yield. Compound $\mathbf{5 f}$ was configurationally stable in solid form; however, we observed slow isomerization in solution $\left(\mathrm{CDCl}_{3}\right)$ at ambient temperature and in daylight (from $E / Z$ 93:7 to $66: 33$ after 10 days). Reactions with ketones, even electrophilic and non-enolizable ones such as 4,4'-dichlorobenzophenone or 2,2,2-trifluoroacetophenone, did not provide the expected alkene products.

Next, we investigated analogous HWE reactions of isomeric phosphonate $\mathbf{4}$ with various aldehydes. Good yields of products 6 were obtained with both aromatic and aliphatic aldehydes. In contrast to most of the reactions with $\mathbf{3}$, phosphonate $\mathbf{4}$ gave exclusively $E$-isomers of $\mathbf{6}$ (Table 3 ). This improved selectivity can be explained by relative differences in the stabilities and

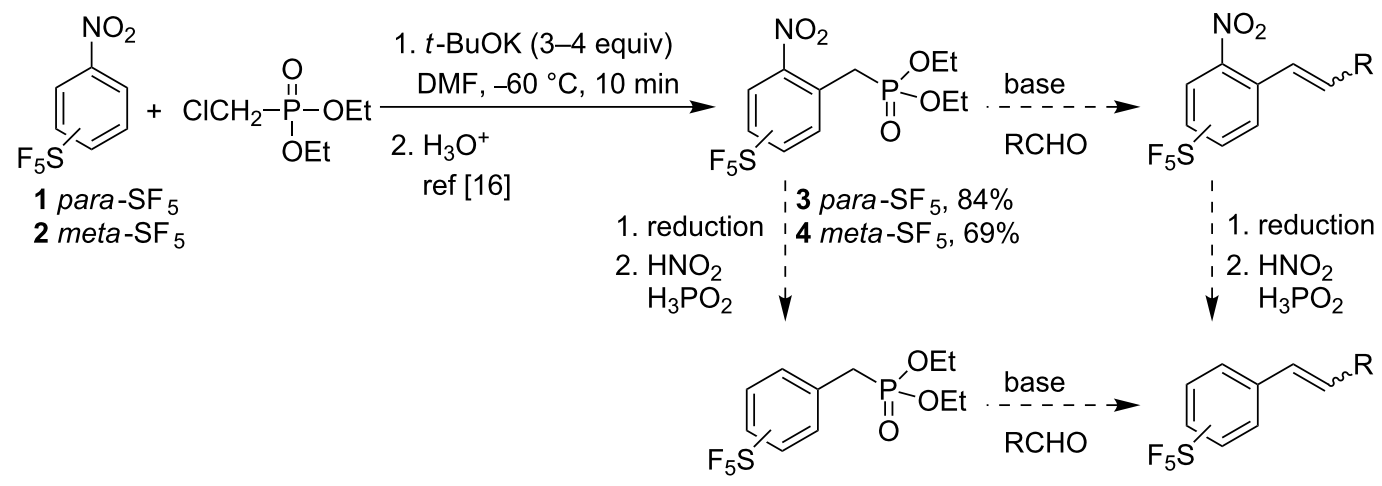


Table 1: Optimization of HWE reaction of phosphonate 3 with benzaldehyde.<smiles>CCOP(=O)(Cc1cc(S(F)(F)(F)(F)F)ccc1[N+](=O)[O-])OCC</smiles>

3

$5 a$

\begin{tabular}{|c|c|c|c|c|c|c|}
\hline Entry & Base (equiv) & Solvent & $T\left({ }^{\circ} \mathrm{C}\right)$ & $t(\min )$ & $5 \mathbf{a}$, Yield $(\%)^{a}$ & $E / Z^{b}$ \\
\hline $1^{c}$ & $t$-BuOK (3.0) & DMF & 50 & 960 & 83 & $97: 3$ \\
\hline $2^{c}$ & $t$-BuOK (3.0) & THF & 50 & 120 & 58 & $>98: 2$ \\
\hline 3 & $t$-BuOK (3.0) & THF & 50 & 240 & 98 & $95: 5$ \\
\hline 4 & $t$-BuOK (1.8) & THF & 50 & 60 & 98 & $94: 6$ \\
\hline 5 & $t$-BuOK (1.3) & THF & 50 & 60 & $94(68)$ & $95: 5$ \\
\hline 6 & $n$-BuLi (2.0) & THF & $\mathrm{rt}$ & 30 & 93 & $92: 8$ \\
\hline 7 & LiHMDS (2.0) & THF & $\mathrm{rt}$ & 60 & 59 & $92: 8$ \\
\hline 8 & $\mathrm{~K}_{2} \mathrm{CO}_{3}(3.0)$ & $\mathrm{MeCN}$ & 60 & 960 & 81 & $91: 9$ \\
\hline 9 & $\mathrm{Cs}_{2} \mathrm{CO}_{3}(1.8)$ & $\mathrm{MeCN}$ & $\mathrm{rt}$ & 360 & 97 & $93: 7$ \\
\hline 10 & $\mathrm{KOH}(1.3)$ & THF & $\mathrm{rt}$ & 7 & 89 & $95: 5$ \\
\hline 11 & $\mathrm{KOH}(1.9)$ & THF & $\mathrm{rt}$ & 7 & 92 & $95: 5$ \\
\hline 12 & $\mathrm{KOH}(1.8)$ & $\mathrm{MeCN}$ & $\mathrm{rt}$ & 60 & $90(67)$ & $97: 3$ \\
\hline 13 & $\mathrm{KOH}(1.8)$ & $\mathrm{MeCN}^{\mathrm{d}}$ & $\mathrm{rt}$ & 30 & $98(84)$ & $98: 2$ \\
\hline
\end{tabular}

aDetermined by GCMS analysis (in brackets isolated yield). ${ }^{b}$ Determined by GCMS analysis of the crude reaction mixture. ${ }^{\mathrm{c}} \mathrm{Phosphonate} 3$ was prepared in situ from 1 and diethyl chloromethylphosphonate $\left(-60^{\circ} \mathrm{C}, 10 \mathrm{~min}\right)$. ${ }^{\mathrm{d}}$ Water (8 equiv) was added.

Table 2: HWE reactions of phosphonate 3 with aldehydes.

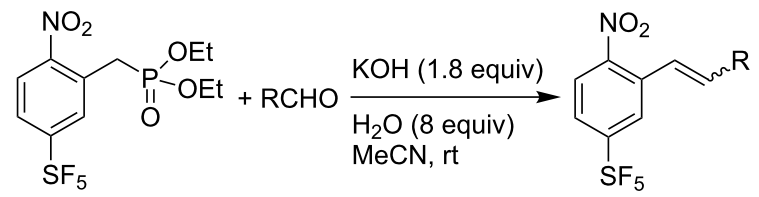

\begin{tabular}{lllll}
\hline Entry & $\mathrm{R}$ (equiv) & $t(\min )$ & $\mathbf{5}$, Yield $(\%)^{\mathrm{a}}$ & $\mathbf{5 , E}, \mathbf{Z}^{\mathrm{b}}$ \\
\hline 1 & $\mathrm{Ph}(1.5)$ & 30 & $\mathbf{5 a}, 84$ & $98: 2$ \\
2 & $4-\mathrm{NO}_{2} \mathrm{C}_{6} \mathrm{H}_{4}(1.7)$ & 5 & $\mathbf{5 b}, 84$ & $>99: 1$ \\
3 & $4-\mathrm{ClC}_{6} \mathrm{H}_{4}(1.1)$ & 30 & $\mathbf{5 c}, 85$ & $98: 2$ \\
4 & $4-\mathrm{MeOC}_{6} \mathrm{H}_{4}(1.5)$ & 90 & $\mathbf{5 d}, 86$ & $99: 1$ \\
5 & $1-\mathrm{Naphthyl} \mathrm{(1.2)}$ & 30 & $\mathbf{5 e}, 80$ & $92: 8$ \\
6 & $(E)-\mathrm{PhCH}=\mathrm{CH}(1.2)$ & 40 & $\mathbf{5 f}, 43^{\mathrm{C}}$ & $93: 7^{\mathrm{d}}$ \\
7 & Et (1.5) & 90 & $\mathbf{5 g}, 67$ & $94: 6$ \\
\hline
\end{tabular}

alsolated yield refers to the pure $E$-isomer unless noted otherwise. bDetermined by GCMS analysis of the crude reaction mixture. 'Isolated yield referring to the $93: 7 \mathrm{E} / \mathrm{Z}$ mixture. ${ }^{\mathrm{d}}$ This ratio changed to 66:33 upon storage in $\mathrm{CDCl}_{3}$ solution at $\mathrm{rt}$ for $10 \mathrm{~d}$.

reactivities of carbanions derived from phosphonates and reactive intermediates. In reactions of phosphoryl-stabilized carbanions with aldehydes, several intermediates are formed reversibly. Less-hindered intermediates $\mathbf{A}$ and $\mathbf{A}^{\prime}$, which eliminate to $E$-alkene, exist in equilibrium with more-hindered inter-

Table 3: HWE reactions of phosphonate 4 with aldehydes.<smiles>CCOP(=O)(Cc1ccc(S(F)(F)F)cc1[N+](=O)[O-])OCC</smiles>

$+\mathrm{RCHO}$
$\mathrm{KOH}$

$\underset{\mathrm{H}_{2} \mathrm{O} \text { (8 equiv) }}{\text { (1.8 equiv) }}$ $\mathrm{MeCN}, \mathrm{rt}$<smiles>[R]C=Cc1ccc(S(F)(F)F)cc1[N+](=O)[O-]</smiles>

6, $E$ only

\begin{tabular}{llll}
\hline Entry & $\mathrm{R}$ (equiv) & $t(\min )$ & $\mathbf{6 ,}$ Yield $(\%)^{\mathrm{a}}$ \\
\hline 1 & $4-\mathrm{NO}_{2} \mathrm{C}_{6} \mathrm{H}_{4}(1.2)$ & 30 & $\mathbf{6 b}, 97$ \\
2 & $4-\mathrm{ClC}_{6} \mathrm{H}_{4}(1.1)$ & 80 & $\mathbf{6 c}, 85$ \\
3 & $4-\mathrm{MeOC}_{6} \mathrm{H}_{4}(1.1)$ & 260 & $\mathbf{6 d}, 76$ \\
4 & $n-\mathrm{C}_{6} \mathrm{H}_{13}(1.1)$ & 90 & $\mathbf{6 h}, 84$ \\
\hline
\end{tabular}

asolated yield.

mediates B and B' giving $Z$-alkene (Scheme 2). In our reactions, the stabilization of the negative charge in the deprotonated phosphonate is higher for $\mathbf{4}$ than for $\mathbf{3}$ due to conjugation of the negative charge with the $\mathrm{SF}_{5}$ group in the former case $\left(\sigma_{\mathrm{I}}\left(\mathrm{SF}_{5}\right)=0.55, \sigma_{\mathrm{R}}\left(\mathrm{SF}_{5}\right)=0.11\right.$ [5]). Consequently, $4^{-}$is more stable and less nucleophilic than $\mathbf{3}^{-}$, and therefore, in comparison to the A-to-B equilibrium the A'-to-B' equilibrium is shifted more towards $\mathbf{A}$ ' providing only $(E)-\mathbf{6}$ product (Scheme 2). 


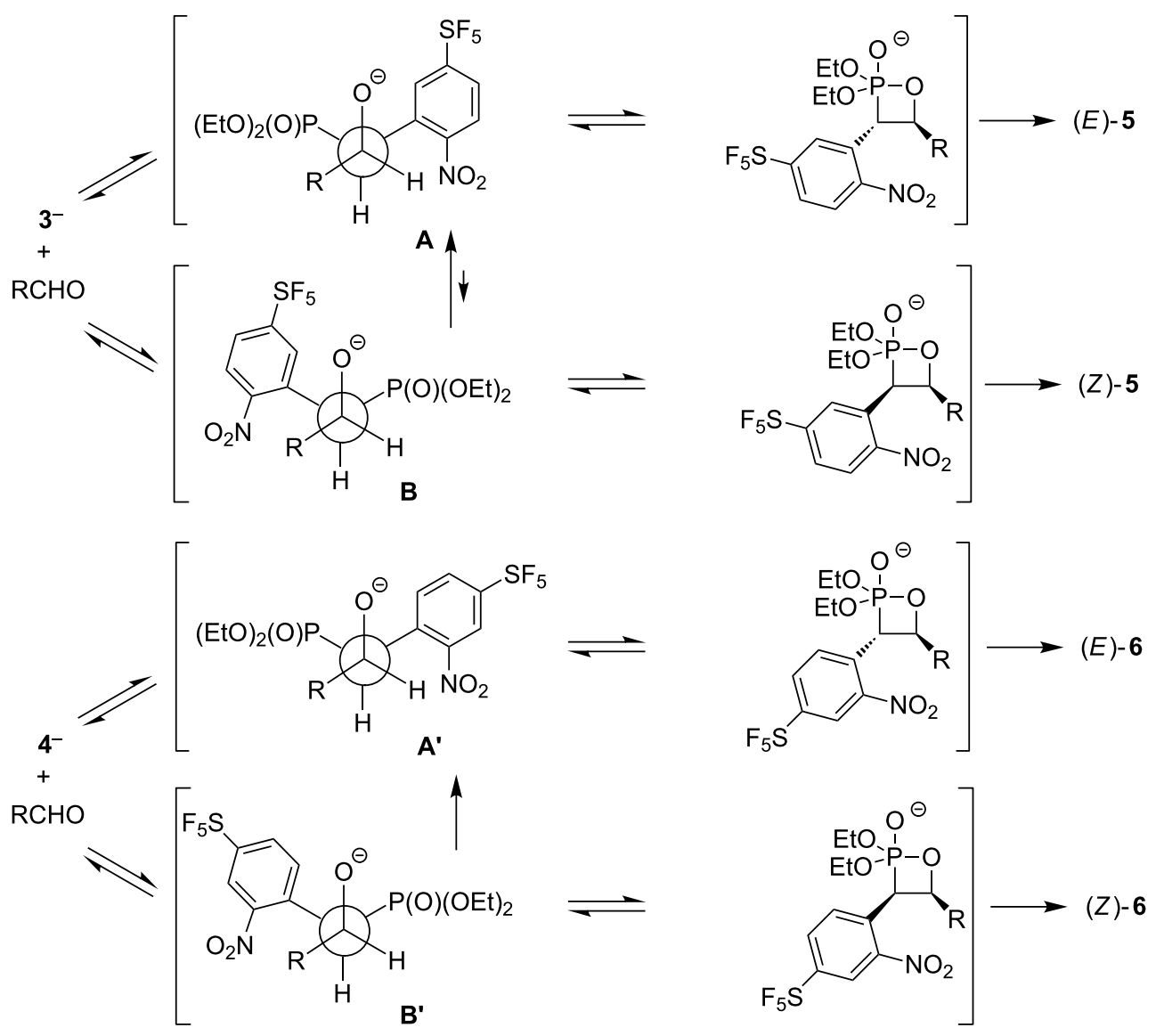

Scheme 2: Reactive intermediates involved in HWE reactions to alkenes 5 and $\mathbf{6}$.

To demonstrate the versatility of this methodology leading to new carbon-substituted $\mathrm{SF}_{5}$-benzenes, several transformations of primary products $\mathbf{5}$ and $\mathbf{6}$ were performed. Reduction with hydrogen $(1 \mathrm{~atm})$ in the presence of catalytic Raney nickel did not provide full conversion to the respective anilines. Furthermore, the reaction mixtures contained products 7 and $\mathbf{8}$. At higher pressure (20 atm), complete nitro group and $\mathrm{C}=\mathrm{C}$ reduction of stilbenes $\mathbf{5}$ and $\mathbf{6}$ to compounds $\mathbf{7}$ and $\mathbf{8}$, respectively, took place (Table 4). Several other conditions were tested, but no system for selective reduction of the nitro group was found.

Diazotization was carried out with the aim to prepare 1,2diarylethane 9d from aniline 8d (Scheme 3). A combination of sodium nitrite and phosphoric acid was used. (With $\mathrm{HCl}$, substitution of the amino function by a chlorine atom was observed, and the use of $\mathrm{H}_{2} \mathrm{SO}_{4}$ resulted in low solubility of the formed anilinium in water.) An ether cosolvent ( $\mathrm{Et}_{2} \mathrm{O}$ or $t$ - $\left.\mathrm{BuOMe}\right) \mathrm{im}$ proved the yield compared to aqueous or aqueous/THF mixtures. The presence of reducing hypophosphorous acid provided a mixture of the expected $\mathbf{9 d}$ and the cyclized product 10d resulting from electrophilic aromatic substitution of the
Table 4: Hydrogenation of stilbene derivatives 5 and 6 .<smiles>[R]CCc1cc([X])c([Y])cc1N</smiles>

\begin{tabular}{llllll}
\hline Entry & $\mathbf{5}$ or $\mathbf{6}$ & $\mathrm{X}$ & $\mathrm{Y}$ & $\mathrm{R}$ & $\mathbf{7}$ or $\mathbf{8}$, Yield (\%) \\
\hline 1 & $\mathbf{5 a}$ & $\mathrm{SF}_{5}$ & $\mathrm{H}$ & $\mathrm{Ph}$ & $\mathbf{7 a}, 87$ \\
2 & $\mathbf{6 c}$ & $\mathrm{H}$ & $\mathrm{SF}_{5}$ & $4-\mathrm{ClC}_{6} \mathrm{H}_{4}$ & $\mathbf{8 c}, 64$ \\
3 & $\mathbf{6 d}$ & $\mathrm{H}$ & $\mathrm{SF}_{5}$ & $4-\mathrm{MeOC}_{6} \mathrm{H}_{4}$ & $\mathbf{8 d}, 82$ \\
\hline
\end{tabular}

alsolated yield.

substituted phenyl cation intermediate (formed by the decomposition of the diazonium salt), to the electron-rich anisole ring in an unusual meta-position relative to the methoxy group. The more activated para-position is unavailable, and the reaction in ortho-positions would give too strained a product. The formation of the cyclized side product is not restricted to compounds 


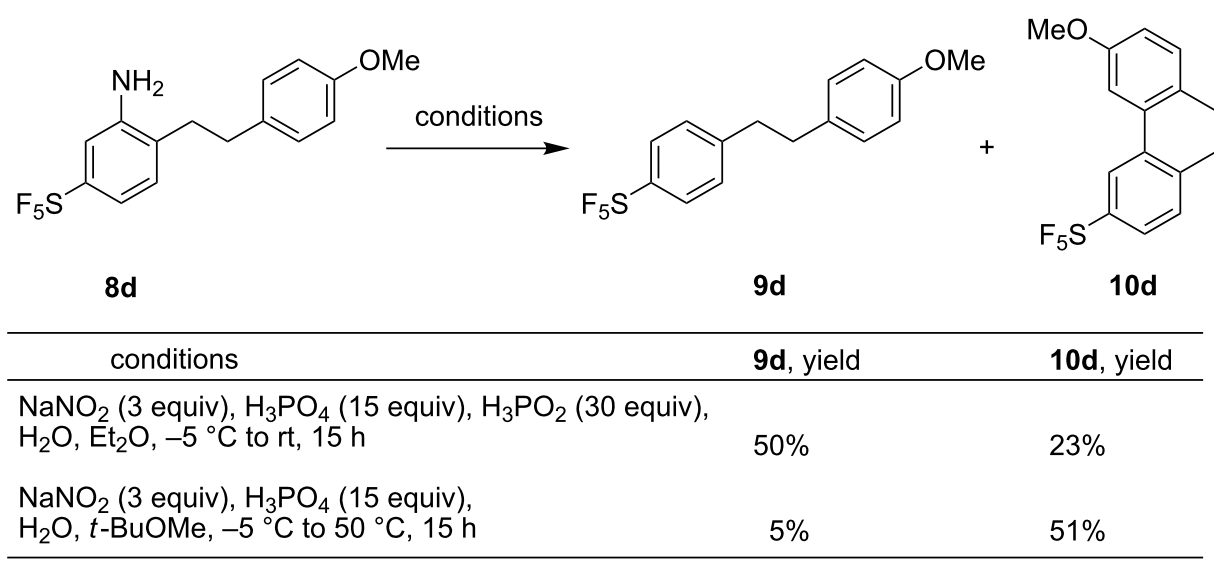

Scheme 3: Diazotization/reduction of $\mathbf{8 d}$ to $\mathbf{9 d}$ and the formation of unexpected cyclized product $\mathbf{1 0 d}$.

with an electron-donor substituent on the aromatic ring. Similarly to $\mathbf{8 d}$, the cyclic product was detected by GCMS in diazotization of compound $\mathbf{8 c}$ (product not isolated). Compound $\mathbf{1 0 d}$ was fully characterized by spectroscopic methods, and the yield was increased to $51 \%$ by performing the diazotization reaction in the absence of a reducing reagent (Scheme 3). Aromatization of $10 \mathrm{~d}$ by oxidation using CAN was performed to give $\mathrm{SF}_{5}-$ substituted phenanthrene 11d in good yield (Scheme 4).<smiles>COc1ccc2c(c1)-c1cc(S(F)(F)F)ccc1CC2</smiles>

$10 d$

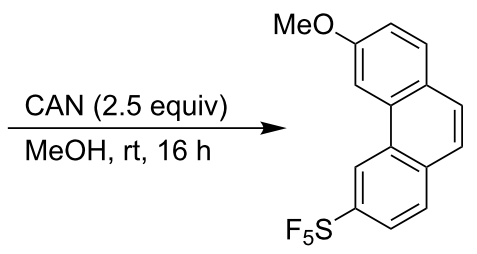

$11 d, 77 \%$
Scheme 4: Synthesis of substituted phenanthrene 11d.

To avoid problems with alkene reduction and electrophilic aromatic substitution during nitro group removal, we decided to try a different approach to the general synthesis of $\mathrm{SF}_{5}$ containing stilbene derivatives, as demonstrated in the synthesis of 13d shown in Scheme 5. The nitro group in phospho- nate 4 was removed by a reduction/diazotization/reduction sequence to give phosphonate $\mathbf{1 2}$ in good yield. The following HWE reaction with 4-methoxybenzaldehyde afforded $\mathbf{1 3 d}$ in good yield, exclusively as the $E$-isomer.

\section{Conclusion}

In conclusion, we have shown access to (E)-2-nitro-1-alkenyl(pentafluorosulfanyl)benzenes from nitro-(pentafluorosulfonyl)benzenes by VNS reaction with diethyl chloromethylphosphonate followed by stereoselective HWE reaction with aldehydes. Reduction of (E)-2-nitro-1-alkenyl-(pentafluorosulfanyl)benzenes provided 2-(2-arylethyl)-(pentafluorosulfanyl)anilines, and the formation of $(E)$-1-alkenyl-4-(pentafluorosulfanyl)benzenes was demonstrated from diethyl 4-(pentafluorosulfanyl)benzylphosphonates.

\section{Supporting Information}

\section{Supporting Information File 1}

Experimental details and characterization data for all new compounds.

[http://www.beilstein-journals.org/bjoc/content/ supplementary/1860-5397-8-131-S1.pdf]<smiles>O=[N+]([O-])c1cc(S(F)(F)(F)(F)F)ccc1CP(=O)([O-])O</smiles>

4

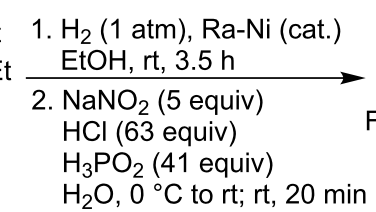<smiles>CCOP(=O)(Cc1ccc(S(F)(F)F)cc1)OCC</smiles>

$12,79 \%$

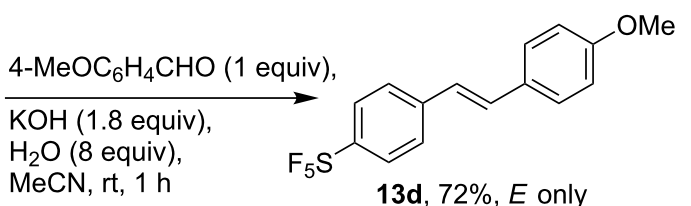

13d, $72 \%, E$ only 


\section{Acknowledgements}

This work was financially supported by the Academy of Sciences of the Czech Republic (RVO: 61388963) and by the Grant Agency of the Czech Republic (P207/12/0072).

\section{References}

1. Case, J. R.; Ray, N. H.; Roberts, H. L. J. Chem. Soc. 1961, 2066-2070. doi:10.1039/JR9610002066

2. Ray, N. H. J. Chem. Soc. 1963, 1440-1441. doi:10.1039/JR9630001440

3. Merrill, C. I.; Cady, G. H. J. Am. Chem. Soc. 1961, 83, 298-300. doi:10.1021/ja01463a011

4. Dudley, F. B.; Cady, G. H.; Eggers, D. F., Jr. J. Am. Chem. Soc. 1956, 78, 1553-1557. doi:10.1021/ja01589a013

5. Kirsch, P. Synthesis of complex Organofluorine Compounds. Modern Fluoroorganic Chemistry; Wiley-VCH: Weinheim, Germany, 2004; pp 146-156. doi:10.1002/352760393X.ch2

6. Winter, R. W.; Dodean, R. A.; Gard, G. L. SF 5 -Synthons: Pathways to Organic Derivatives of $\mathrm{SF}_{6}$. In Fluorine-Containing Synthons; Soloshonok, V. A., Ed.; ACS Symposium Series, Vol. 911; American Chemical Society: Washington, DC, 2005; pp 87-118. doi:10.1021/bk-2005-0911.ch004

7. Kirsch, P.; Röschenthaler, G.-V. Functional Compounds Based on Hypervalent Sulfur Fluorides. In Current Fluoroorganic Chemistry; Soloshonok, V. A.; Mikami, K.; Yamazaki, T.; Welch, J. T.; Honek, J. F. Eds.; ACS Symposium Series, Vol. 949; American Chemical Society: Washington, DC, 2007; pp 221-243. doi:10.1021/bk-2007-0949.ch013

8. Aït-Mohand, S.; Dolbier, W. R., Jr. Org. Lett. 2002, 4, 3013-3015. doi:10.1021/ol026483o

9. Dolbier, W. R., Jr.; Aït-Mohand, S.; Schertz, T. D.; Sergeeva, T. A.; Cradlebaugh, J. A.; Mitani, A.; Gard, G. L.; Winter, R. W.; Thrasher, J. S. J. Fluorine Chem. 2006, 127, 1302-1310. doi:10.1016/j.jluchem.2006.05.003

10. Bowden, R. D.; Greenhall, M. P.; Moilliet, J. S.; Thomson, J. The Preparation Of Fluorinated Organic Compounds. WO Patent WO1997005106, Feb 13, 1997.

11. Bowden, R. D.; Comina, P. J.; Greenhall, M. P.; Kariuki, B. M.; Loveday, A.; Philp, D. Tetrahedron 2000, 56, 3399-3408. doi:10.1016/S0040-4020(00)00184-8

12. Chambers, R. D.; Spink, R. C. H. Chem. Commun. 1999, 883-884. doi:10.1039/A901473J

13. Umemoto, T.; Garrick, L. M.; Saito, N. Beilstein J. Org. Chem. 2012, 8, 461-471. doi:10.3762/bjoc.8.53

14. Umemoto, T.; Chika, J. Processes for preparing 1,3-dinitro-5-(pentafluorosulfanyl)benzene and its intermediates. U.S. Patent Appl. 2011/0301382 A1, Dec 8, 2011.

15. Beier, P.; Pastýŕíková, T.; Vida, N.; lakobson, G. Org. Lett. 2011, 13, 1466-1469. doi:10.1021/ol2001478

16. Beier, P.; Pastýř́íková, T.; lakobson, G. J. Org. Chem. 2011, 76, 4781-4786. doi:10.1021/jo200618p

17. Beier, P.; Pastýŕíková, T. Tetrahedron Lett. 2011, 52, 4392-4394. doi:10.1016/j.tetlet.2011.06.011

18. Pastýříková, T.; lakobson, G.; Vida, N.; Pohl, R.; Beier, P. Eur. J. Org. Chem. 2012, 2123-2126. doi:10.1002/ejoc.201200127

19. Vida, N.; Beier, P. J. Fluorine Chem., in press. doi:10.1016/j.jfluchem.2012.04.001

20. Crowley, P. J.; Mitchell, G.; Salmon, R.; Worthington, P. A. Chimia 2004, 58, 138-142.
21. Kirsch, P.; Bremer, M.; Heckmeier, M.; Tarumi, K. Angew. Chem., Int. Ed. 1999, 38, 1989-1992. doi:10.1002/(SICl)1521-3773(19990712)38:13/14<1989::AID-ANIE198 9>3.0.CO;2-K

22. Sheppard, W. A. J. Am. Chem. Soc. 1962, 84, 3064-3072. doi:10.1021/ja00875a006

23. Maryanoff, B. E.; Reitz, A. B. Chem. Rev. 1989, 89, 863-927. doi:10.1021/cr00094a007

24. Boutagy, J.; Thomas, R. Chem. Rev. 1974, 74, 87-99. doi:10.1021/cr60287a005

25. Rein, T.; Pedersen, T. M. Synthesis 2002, 579-594. doi:10.1055/s-2002-23535

26. Ando, K. J. Synth. Org. Chem., Jpn. 2000, 58, 869-876.

27. Ando, K. J. Org. Chem. 1997, 62, 1934-1939. doi:10.1021/jo970057c

28. Still, W. C.; Gennari, C. Tetrahedron Lett. 1983, 24, 4405-4408. doi:10.1016/S0040-4039(00)85909-2

\section{License and Terms}

This is an Open Access article under the terms of the Creative Commons Attribution License

(http://creativecommons.org/licenses/by/2.0), which permits unrestricted use, distribution, and reproduction in any medium, provided the original work is properly cited.

The license is subject to the Beilstein Journal of Organic Chemistry terms and conditions:

(http://www.beilstein-journals.org/bjoc)

The definitive version of this article is the electronic one which can be found at: $\underline{\text { doi: } 10.3762 / \text { bjoc. } 8.131}$ 